\title{
Cloacal Sphincter
}

National Cancer Institute

\section{Source}

National Cancer Institute. Cloacal Sphincter. NCI Thesaurus. Code C34129.

A muscle surrounding the cloacal membrane in the developing embryo; the posterior part forms the external anal sphincter. 